\title{
Las Voces que Somos, um Enunciado da Mídia Dialógica Indígena para a Libertação
}

\section{Las Voces que Somos, an Indigenous Dialogic Media Utterance for Liberation}

\author{
C LA UDIA MA GA L LANES-B LA N C O
}

Universidad Iberoamericana Puebla, Departamento de Humanidades. San Andrés Cholula - Puebla, México

\section{RESUMO}

Neste artigo, reviso as teorias de Paulo Freire da ação antidialógica e da ação cultural dialógica, bem como a noção de diálogo e enunciados de Bakhtin. Com base nisso, enfoco um projeto de comunicação de mídia indígena no estado de Oaxaca, México, e em um de seus produtos midiáticos que considero um enunciado de mídia. Defendo que os temas centrais do projeto de comunicação e uma série de rádio que os abordam, refletem o diálogo entre os comunicadores indígenas e a realidade atual que enfrentam, que ameaça seus territórios e modos de vida. O diálogo é um componente fundamental de um processo comunicativo que molda nossa compreensão do sistema-mundo e torna as diferenças e desigualdades evidentes.

Palavras-chave: Paulo Freire, Mikhail Bakhtin, diálogo, enunciações da mídia, comunicação indígena

\begin{abstract}
In this article I review Paulo Freire's theories of anti-dialogic action and of dialogic cultural action, as well as Bakhtin's notion of dialogue and utterances. Drawing from these, I focus on a communication project of Indigenous media and communication practitioners from the state of Oaxaca, Mexico, and on one of its media products which I consider a media utterance. I argue that the core themes of the communication project and a radio series that addresses them reflect the dialogue between Indigenous communication practitioners and the ongoing reality they face that menaces their territories and ways of life. Dialogue is a key component of a communicative process that shapes our understanding of the world-system and makes differences and inequalities evident.
\end{abstract}

Keywords: Paulo Freire, Mikhail Bakhtin, dialogue, media utterances, Indigenous communication

\footnotetext{
a Professora do Departamento de Humanidades, da Universidad Iberoamericana Puebla, no México.

É cofundadora do mestrado em Comunicação para a Mudança Social nessa instituição. Orcid: https://orcid.org/0000-00033053-8568. E-mail: claudia. magallanes@iberopuebla.mx
} 


\section{VIOLÊNCIA CONTRA OS POVOS INDÍGENAS NO MÉXICO}

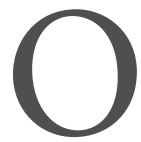

$S$ POVOS INDÍGENAS têm vivido constantemente em situações de violência no México, do racismo instilado nas formas cotidianas de vida (Castellanos Guerrero et al., 2007), muitas vezes disfarçado de racismo cordial (Gómez Izquierdo \& Sánchez, 2012), à violência exercida pelas autoridades por meio de políticas públicas e programas assimilacionistas, que buscam aniquilar culturas indígenas sob o pretexto do desenvolvimento (Castells i Talens, 2011; Korsbaek \& Sámano-Rentería, 2007). Mulheres e homens indígenas vivem, no México, imersos em violência estrutural (Galtung, 1996), expressa em exclusão social e exploração, bem como na negação de sua cultura e identidade.

Por meio do exercício da violência e do medo, vários megaprojetos de natureza extrativista avançaram em territórios indígenas. As empresas extrativistas praticam violência tanto pela natureza de seus empreendimentos quanto pelos mecanismos utilizados para garantir o acesso aos territórios, que envolvem repressão, coerção e até violência criminal (Durán Matute \& Moreno, 2021). As comunidades indígenas têm resistido a várias tentativas de incluí-las nos modelos dominantes de organização social, política e econômica. Embora tenham muitas especificidades que as tornam únicas, elas compartilham uma série de elementos que lhes permitem se identificar umas com as outras. Um deles é a constante agressão e pilhagem de suas terras e territórios. O processo de totalização capitalista (Tischler, 2013) tem utilizado formas culturais, territoriais, linguísticas e outras de colonização para expandir e garantir sua sobrevivência. Estamos, atualmente, vivenciando uma escalada na agressão contra esses povos devido à proliferação de projetos extrativistas e desapropriação (Harvey, 2005), derivados de políticas neoliberais, que resultaram no aumento excessivo e acrítico de concessões a empresas transnacionais para mineração, energia eólica, hidrelétrica, agricultura de larga escala, desenvolvimento turístico etc.

Essa expansão ataca os modos de vida das comunidades indígenas, que produziram diversos mecanismos de resistência, obedecendo aos contextos sócio-histórico, político e econômico do momento. "A forma como os povos indígenas representam a natureza, sua relação com ela e sua conservação, é um elemento-chave em sua luta pela autodeterminação" (Magallanes-Blanco, 2016, p. 135). O saqueio do território também é uma pilhagem cultural, de modos de vida, de línguas, de cosmogonias. Dessa forma, a luta dos indígenas pela defesa da terra e do território é uma luta pela vida. 


\section{O contexto oaxacano}

O estado de Oaxaca está localizado no sudeste do México. É dividido em oito regiões, com 570 municípios em 30 distritos. Em 2020, o território de Oaxaca era habitado por 4.132 .148 pessoas (Instituto Nacional de Estadística Geografía e Informática [Inegi], 2020). Oaxaca é historicamente um dos estados mais pobres do país. No geral, em $2018,66,4 \%$ da população vivia em situação de pobreza e 13,2\% da população com 15 anos ou mais, segundo a Pesquisa Intercensitária 2015, era analfabeta. Oaxaca é a entidade mexicana com a maior diversidade étnica, cultural, linguística e natural, que se expressa na presença dos povos indígenas Amuzgo, Cuicateco, Chatino, Chinanteco, Chocholteco, Chontal, Huave, Ixcateco, Mazateco, Mixe, Mixteco, Náhuatl, Triqui, Zapoteco e Zoque, reconhecidos desde 1990 no artigo 16 da Constituição local (Inegi, 2020).

Em 2020, 43\% da população total do estado era indígena, ou seja, 1.780 .303 (929.478 mulheres); e 194.474 eram considerados afrodescendentes; $31,2 \%$ da população de Oaxaca fala alguma língua indígena, $89 \%$ também falam espanhol e $11 \%$ não falam espanhol (Inegi, 2020).

De acordo com Servicios para una Educación Alternativa A.C., "Em Oaxaca há áreas ou regiões dominadas por famílias que acreditam ser os donos da vida das pessoas, nas quais prevalecem a impunidade e exceções à lei" (Educa, 2021, p. 2). No território de Oaxaca, o megaprojeto do Corredor Interoceânico faz parte do Plano Nacional de Desenvolvimento 2019-2024.

O Corredor Interoceânico cobriria 79 municípios dos estados de Oaxaca e Veracruz, ou 98, incluindo Tabasco e Chiapas. Inclui a recuperação da ferrovia para o transporte de mercadorias e a ligação dos dois oceanos [Atlântico e Pacífico], mas também a construção de rodovias para garantir a comunicação, dez parques industriais; um oleoduto para conexão com a refinaria dos Bocas e um gasoduto para abastecer a região com gás natural proveniente dos Estados Unidos. Inclui também a ampliação dos portos de Coatzacoalcos e Salina Cruz, e a construção de um porto comercial de petróleo também em Salina Cruz. Esse corredor também poderia envolver novos projetos de energia e mineração (Durán Matute \& Moreno, 2021, p. 28)

Embora o discurso do governo enfoque o desenvolvimento econômico, o projeto, na realidade, devastaria a região, área rica em recursos naturais que se tornará propriedade de grandes empresas. Durán Matute e Moreno (2021) explicam da seguinte forma, 
Se realizadas, alterariam a geografia física, causariam mudanças nas correntes oceânicas, aumentariam a densidade populacional, afetariam a pesca da qual as pessoas vivem, ameaçariam ainda mais suas terras, rios e mares, gerariam conflitos sociais, causariam escassez de água e desapropriação de terras, tornariam a vida ainda mais precária e aumentariam a violência, a insegurança e o tráfico de drogas. Assim, a chegada de megaprojetos no México esconde uma guerra de extermínio disfarçada de "desenvolvimento", "emprego" e "bem-estar". Não se consideram os efeitos que eles terão sobre os povos indígenas, a região e o planeta. (p. 29)

$\mathrm{Na}$ região do Istmo, em que está previsto o Corredor Interoceânico, três estações de rádio comunitárias indígenas fazem parte do projeto Comunicação Transformadora para o Cuidado da Vida e do Território do México à América Central, implantado pela Ojo de Agua Comunicación.

\section{COMUNICAÇÃO TRANSFORMADORA PARA O CUIDADO DA VIDA E DO TERRITÓRIO}

Nascida em Oaxaca, México, em 1998, a Ojo de Agua Comunicación (Comunicación Indígena S.C.) é uma organização de comunicadores, sem fins lucrativos, dedicada a promover a comunicação indígena e comunitária, produzindo programas de rádio e vídeo culturais e educacionais, bem como colaborando com outros coletivos e organizações em processos de comunicação e mídias comunitárias indígenas no México e outras regiões da América Latina (Magallanes-Blanco \& Monteforte, 2019).

Os objetivos da Ojo de Agua Comunicación são: 1) fortalecer as capacidades que possibilitem a apropriação de instrumentos e a criação de espaços de comunicação, principalmente para os povos indígenas; 2 ) contribuir para a compreensão e o respeito à diversidade cultural, simplificando a informação, a comunicação e a expressão dentro das comunidades indígenas e para o resto da sociedade; 3) facilitar o encontro, o intercâmbio e a retroalimentação entre os comunicadores indígenas em Oaxaca, assim como com outras regiões e países; e 4) apoiar outras organizações da sociedade civil no fortalecimento de suas próprias estratégias de comunicação (Magallanes-Blanco \& Monteforte, 2019).

O trabalho da Ojo de Agua está fortemente enraizado nas necessidades e desafios da comunidade e na comunicação indígena no México hoje; em compreender, viver e exercitar a comunicação como um direito, usando-a como instrumento de defesa comunitária, social e política. "Dado o clima de violência generalizada, ataque territorial, e a escassez de mídias anti-hegemônicas existentes e ferramentas de comunicação com foco de gênero" 
(Ojo de Agua Comunicación, 2020, p. 1), a organização decidiu realizar o projeto Comunicação Transformadora para o Cuidado da Vida e do Território do México à América Central.

Com financiamento da Kultura Comunicación y Desarrollo (KCD), o projeto foi implementado entre 2018 e 2020, com três linhas principais de ação: 1) fortalecimento das capacidades de comunicadores indígenas de nove estações de rádio comunitárias, em quatro regiões do estado de Oaxaca, por meio de treinamento em cursos formais, oficinas e reuniões; 2) organização comunitária para o cuidado da vida e do território por meio de rádios comunitárias, com a afirmação da identidade cultural e a contribuição das novas gerações. Isso foi feito a partir da produção e difusão de conteúdo radiofônico, com base na identidade cultural e relacionado ao cuidado da vida e do território, com uma perspectiva de gênero, e também por eventos comunitários para tornar as questões sociais visíveis e promover os vínculos comunitários; 3 ) articulação da mídia comunitária no México e na América Central para o apoio público político à causa e à visibilidade das violações de direitos e das alternativas sustentáveis. Isso foi feito por meio de encontros, seminários, festivais e exposições que permitiram compartilhar produtos, experiências, conhecimentos e formas de luta e resistência.

O projeto teve três eixos temáticos: a perspectiva de gênero, o cuidado com a vida e o território, e a cultura de paz.

\section{A perspectiva de gênero}

Em 2015, a Ojo de Agua Comunicación decidiu integrar uma perspectiva de gênero na organização e no projeto desenvolvido com várias estações de rádio comunitárias em diversas regiões do estado de Oaxaca. Em 2017, incorporaram o gênero como eixo transversal tanto dentro da organização quanto no trabalho desenvolvido com as estações de rádio comunitárias. "Para aqueles que fazem parte do coletivo, trabalhar a partir de uma perspectiva de gênero implica assumir uma postura política, um compromisso ético de não permitir injustiças e violações dos direitos das mulheres, e contribuir para eliminar a desigualdade de gênero" (Zurita Cruz, s.d., p. 4).

A Ojo de Agua busca fornecer informações para a prevenção não só da agressão, mas também do alcoolismo, da violência física e de gênero. Para isso, confiam nos benefícios do uso de formatos de rádio para informar, conscientizar e potencialmente prevenir a violência de gênero. Dizem, "nosso trabalho é falar sobre gênero de uma maneira inteligente que oferece uma saída. Queremos falar sobre gênero para mudar a violência" (Magallanes-Blanco \& Di Lauro Bentivogli, 2021, p. 11). Eles acreditam que a abordagem do gênero 
permite um olhar amplo que contempla as perspectivas de mulheres e homens, bem como de adolescentes e crianças, a fim de construir diálogos dentro e a partir da comunidade, criando conteúdos voltados à prevenção. Também estão cientes de que é necessário fazer alianças no nível comunitário ou com autoridades para que, caso uma mulher queira fazer uma reclamação, com base em uma novela de rádio ou sociodrama, saiba a quem recorrer.

\section{O cuidado com a vida e o território}

O compromisso da Ojo de Agua em relação ao cuidado com a vida e com o território é informar de forma assertiva, incluindo em suas mensagens elementos com os quais as pessoas possam se relacionar e que sejam úteis. A defesa do território está intimamente relacionada à saúde, à educação e à alimentação. A prevenção está voltada aos megaprojetos e, por isso, é importante deixar claro o que são, a qual modelo de vida correspondem, quem se beneficia do modelo de desenvolvimento proposto e como prejudicam as comunidades e os povos. As ameaças representadas pelos megaprojetos são comuns a todos os territórios, o que faz necessário unir as comunidades e enfatizar valores como a reciprocidade, a celebração coletiva ou Guelaguetza nas produções de rádio, de modo que as pessoas se reconheçam nas histórias e, idealmente, despertem ou mantenham o desejo de semear a terra.

A organização acredita que é necessário que as comunidades discutam as condições em que vivem e as decisões relativas ao cultivo da terra. A Ojo de Agua sente que pode contribuir nesse sentido fornecendo informações e incentivando a reflexão, pois, embora haja uma defesa da população do território e da vida, há também abusos de recursos e poder e grandes projetos extrativistas, já existentes ou em instalação, em ambientes comunitários, tais como projetos de mineração, hidrelétrica, monocultura, turismo e desenvolvimento.

A Ojo de Agua desenvolveu-se com uma agenda comunicativa e formativa que busca informar de maneira clara e acessível sobre quem se beneficia dos megaprojetos. Essa agenda tem o papel de contrainformação, em uma sociedade permeada por um sistema ocidental dominante, enraizado no que eles chamam de "a trama do poder". Esta é composta por capitalismo, colonialismo e patriarcado, três formas conectadas de dominação que evidenciam a exploração da terra, o racismo e a pobreza, e andam lado a lado. O papel da Ojo de Agua é expor essa teia de poder e se contrapor a ela por meio de seu trabalho comunicativo. A organização sabe que é preciso pensar em uma estratégia múltipla que engloba emergências, necessidades urgentes e sentidas no cotidiano das comunidades, bem como aspectos de longo prazo, que coloquem o ser humano 
acima dos interesses econômicos e o relacionamento dos seres vivos em condições de equidade, contemplando diálogos intergeracionais que permitem o pensamento de longo prazo a partir de contextos específicos e que dão origem à alegria e ao prazer.

\section{Construindo uma cultura de paz}

Esse eixo temático é o mais recente na agenda de trabalho da Ojo de Agua. A construção de uma cultura de paz, ou o tema da cultura da paz, emergiu das experiências vividas nos territórios onde estão localizadas as estações de rádio. Nas comunidades, as pessoas constantemente comentavam sobre a situação que viviam (e continuam vivendo) em relação ao tráfico de drogas, ao abuso por parte das autoridades, ao roubo de jovens mulheres e ao linchamento. A Ojo de Agua teve que levar em conta esse contexto de múltiplas violências como parte importante de seu trabalho nas estações de rádio e advocacy nas comunidades.

A Ojo de Agua reconhece que, às vezes, as ameaças e problemas não são externos, mas internos às comunidades, às estações de rádio ou aos coletivos. Assim, abordou a questão da resolução de conflitos para que as emissoras de rádio possam trabalhar sem serem tão expostas ou vulneráveis, e aprendam a lidar com questões complexas de forma equilibrada. Eles reconhecem que o conflito é um elemento constante da vida cotidiana, que não é rígido, e que pensar em termos estáticos não é o melhor caminho a seguir. Além disso, concordam que não é possível falar de paz em um tempo no qual o contexto está repleto de conflitos e violência. No entanto, consideram que as estações de rádio comunitárias ancoram seu trabalho em valores comunitários, razão pela qual constroem uma cultura de paz, e é por isso que a Ojo de Agua pode fornecer-lhes instrumentos para essa construção e para a defesa da comunidade, fortalecendo o tecido comunitário.

Os três eixos temáticos do projeto de comunicação estão ancorados em questões que refletem a colonialidade do poder (Quijano, 1998) que os povos indígenas enfrentam em seu cotidiano. As violências de gênero, contra os territórios e os modos tradicionais de vida, e a perpetrada pelo crime organizado e indivíduos com interesses conflitantes, estão profundamente enraizadas no sistema mundial moderno, colonial, capitalista e patriarcal (Sousa Santos, 2018). São formas atualizadas de conquista e continuam a promover a divisão entre os indivíduos e povos indígenas. A defesa da vida e do território é uma defesa da cultura e de cosmovisões, de formas de conhecer e de crenças que foram apagadas, minadas ou deturpadas pela grande mídia e instituições diversas (educacionais, políticas, religiosas). Os opressores têm muitas estratégias 
e discursos para manipular os povos indígenas e dividi-los, fazê-los acreditar que seus modos de vida são inferiores ou as razões pelas quais o desenvolvimento não pode ser alcançado pela maior parte da sociedade nacional. A Invasão Cultural permeia todas as áreas da vida e está profundamente ligada aos temas centrais do projeto desenvolvido pela Ojo de Agua Comunicación: gênero, defesa da vida e do território, e construção da paz.

Por isso mesmo, as diversas atividades e produções midiáticas ligadas ao projeto de comunicação promovem a colaboração de indígenas e comunidades para tornar suas realidades visíveis, discutindo-as, problematizando-as e enunciando-as. A natureza colaborativa dos projetos une as pessoas no reconhecimento do sistema-mundo e em como agir para transformá-lo. Essa mudança é buscada por meio de diversas atividades organizadas, como festivais de música, feiras gastronômicas e produções de rádio, que são todas ações culturais. Assim, ilustram a relação entre os elementos da teoria de Paulo Freire de ação antidialógica e ação cultural dialógica. Buscam uma transformação dentro das comunidades que pode se expandir além de suas fronteiras para confrontar o sistema-mundo dominante.

\section{DIÁLOGO EM PAULO FREIRE}

Nossa existência humana está profundamente relacionada com nosso uso de palavras. As palavras dão sentido ao mundo em que habitamos e nos conectam com ele. Para Freire (2008), "Não há palavra verdadeira que não seja uma união indissociável entre ação e reflexão e, portanto, não seja práxis. Daí que dizer a palavra verdadeira seja transformar o mundo" (p. 105).

Para transformar o mundo, devemos pronunciá-lo. Ou seja, devemos ser capazes de descrevê-lo, problematizá-lo, remodelá-lo e imaginá-lo, de acordo com nossas necessidades, desejos e realidades. Pronunciar o mundo não é privilégio de alguns poucos. Entretanto, existe um pequeno grupo de pessoas que, ao longo da história, vêm definindo como o mundo se parece, como ele é organizado e quem deve ter acesso a quê (recursos, direitos, benefícios, privilégios) (Sousa Santos, 2018).

Vivemos em um sistema-mundo moderno, capitalista, colonial e patriarcal (Quijano, 1998; Sousa Santos, 2018; Walsh, 2013), no qual os povos indígenas, entre outros grupos, foram desumanizados e segregados por causa de sua suposta condição inferior. Essa inferioridade foi imposta a eles pelos colonizadores. Com base na noção de raça, os colonizadores impuseram um sistema de dominação e repressão, criando a base para o que Quijano (1998) chamou de colonialidade do poder. 
A colonialidade do poder é o padrão constante de dominação, baseado na noção de raça, apoiado em instituições e mecanismos de dominação para preservar a ordem social. Dessa forma, aqueles que foram classificados como inferiores são despossuídos de suas identidades, práticas, culturas, crenças e formas de se relacionar com o mundo e nomeá-lo. Há uma colonialidade do ser (Maldonado-Torres, 2007) na medida em que os indivíduos interiorizam a categoria marginalizada em que foram inseridos. Dessa forma, a vida dos indivíduos é desvalorizada junto a sua cultura e conhecimentos.

Os colonizados são impedidos de elaborar imagens, símbolos, experiências visuais e plásticas subjetivas (Quijano, 1998). Eles têm que submeter sua pronúncia do mundo àquela dos colonizadores (Freire, 2008); são incapazes de representar o mundo como seu, em seus próprios termos, considerando-o suscetível de ser mudado por seus próprios meios e de acordo com seus objetivos (Nakata, 2014; Smith, 2012; Sousa Santos, 2018). Portanto, a autorrepresentação é parte fundamental da agenda política e cultural nas lutas dos povos indígenas.

Para Linda T. Smith (2012), a questão da representação faz parte da agenda de pesquisa e produção do conhecimento indígena. O principal veículo de autorrepresentação dos povos indígenas é a comunicação, materializada em diversos processos, mídias e mensagens que compreendem o verdadeiro pensamento dos povos indígenas. Para Freire (2008), o verdadeiro pensamento é "um pensar que percebe a realidade como processo, que a capta em constante devenir e não como algo estático" (p. 112). O pensamento crítico é um elemento-chave da comunicação. Para Freire, "obstruir a comunicação equivale a transformar as pessoas em objetos" (p. 166), o que é a tarefa dos opressores. Quando a comunicação não é possível, as pessoas são alienadas e reduzidas a meras coisas. O diálogo, então, é uma práxis que conecta as pessoas entre si, dentro e com o mundo. Ele humaniza os indivíduos e torna possível uma revolução autêntica para transformar a realidade. Essa transformação só pode ser feita por aqueles cujas vidas foram oprimidas e buscam a emancipação.

Freire desenvolveu uma teoria da ação antidialógica para explicar os mecanismos de opressão. Ele também desenvolveu uma teoria da ação cultural dialógica para descrever os mecanismos que tornam a emancipação possível.

\section{A teoria da ação antidialógica}

A teoria da ação antidialógica de Freire baseia-se em quatro características: Conquista, Divisão, Manipulação e Invasão Cultural. Elas estão inter-relacionadas e trabalham para dar continuidade à relação antidialógica de indivíduos e grupos uns com os outros e com o mundo. 
A conquista é o modo de manter os indivíduos alienados. Na conquista, a comunicação autêntica não pode ocorrer. Em vez disso, existem comunicados que produzem e circulam mitos que são "indispensáveis à manutenção do status quo. O mito, por exemplo, de que a ordem opressora é uma ordem de liberdade. De que todos são livres para trabalhar onde queiram” (Freire, 2008, p. 182). No México, esses mitos têm prevalecido ao longo do tempo, ao apresentar os povos indígenas como atrasados, inferiores, bárbaros. Eles são criminalizados por defender seus territórios, são caricaturados e reduzidos aos aspectos folclóricos para fins turísticos. Da mesma forma, o mito do desenvolvimento como ponto fundamental para o crescimento e a riqueza de uma nação (e não apenas para alguns) é a base do processo de totalização capitalista. A conquista violenta ainda ocorre nos dias de hoje em muitos territórios indígenas. Materializa-se pelo Estado mexicano, corporações extrativistas, a grande mídia, e continua a ampliar ainda mais a cisão entre aqueles que contam e os que não.

Outra dimensão da ação opressiva contida na teoria da ação antidialógica é dividir e subjugar as massas populares através da divisão. Aqueles que estão no poder têm a necessidade de manter os oprimidos divididos para a continuidade de seu poder. Os opressores "não se podem dar ao luxo de consentir na unificação das massas populares, que significaria, indiscutivelmente, uma séria ameaça à sua hegemonia" (Freire, 2008, p. 184). Portanto, é imperativo que os oprimidos não percebam as regras do sistema-mundo. Existem vários métodos e procedimentos para criar e aprofundar divisões, desde a burocracia estatal até formas de ação cultural para manipular as pessoas. $\mathrm{O}$ projeto Corredor Interoceânico tem sido vendido como meio de ativar a economia da região. Ele dividiu muitas pessoas na região do Istmo, pois algumas o veem como uma fonte de empregos e meio para levar infraestrutura básica de saúde e educação para as comunidades. Por outro lado, há aqueles que se opõem ao projeto, vendo-o como uma ameaça aos territórios, ao meio ambiente e às culturas indígenas. As mídias sociais e a grande mídia tiveram um papel importante na criação de um discurso oficial unificado sobre o projeto, que contribui para a manipulação da informação.

A manipulação é outro elemento da ação antidialógica. É feita por meio de uma série de mitos e discursos. Para Freire (2008), um mito era de particular importância, "o modelo que a burguesia se faz de si mesma às massas com possibilidade de sua ascensão. Para isto, porém, é preciso que as massas aceitem sua palavra" (p. 192). A manipulação serve para impedir os oprimidos de reconhecerem a organização do sistema-mundo. Distrai-los, criando ilusões de mobilidade social ou de desenvolvimento. De acordo com Freire, "se as massas associam à sua emersão, à sua presença no processo histórico, um pensar crítico 
sobre este mesmo processo, sobre sua realidade, então sua ameaça se concretiza na revolução" (p. 194).

Os oprimidos precisam desvendar a manipulação para compreender a lógica da categorização social e o funcionamento do sistema-mundo. Eles precisam ser capazes de pronunciar o mundo como eles o vivem, experimentá-lo, vê-lo e imaginá-lo. A manipulação os impede de olhar para o mundo com seus próprios olhos. É isso que o projeto de comunicação implementado pela Ojo de Agua Comunicación objetiva fazer. Por um lado, torna visíveis as desigualdades de gênero dentro das comunidades, buscando conscientizar sobre as diferentes formas de violência de gênero e preveni-las. Também se concentra em discutir a natureza dos projetos extrativistas que estão sendo implementados nos territórios indígenas e suas relações com o conjunto mais amplo de relações de poder nos níveis regional, nacional e internacional, que incluem questões relacionadas ao crime organizado, tráfico de drogas e humano, migração forçada, entre outros temas.

Para Freire (2008), outra forma de manipulação ocorre em pactos entre os opressores e os oprimidos. Esses pactos podem ser apresentados como resultado de diálogos entre diferentes grupos. No entanto, são antidialógicos e muitas vezes resultam da submissão de uma parte à outra em troca dos benefícios de privilégios para poucos. Esses pactos reforçam o status quo e o funcionamento do sistema-mundo. Em diferentes regiões indígenas, as autoridades locais têm conspirado com empresas de mineração, governos estaduais e até mesmo com cartéis de drogas, permitindo que eles entrem nos territórios sem conhecimento ou consentimento da população.

O elemento final da ação antidialógica é a invasão cultural. "A invasão cultural é a penetração que fazem os invasores no contexto cultural dos invadidos, impondo a estes sua visão do mundo enquanto lhes freiam a criatividade, ao inibirem sua expansão" (Freire, 2008, p. 198). A invasão cultural é sempre violenta e está profundamente ligada à colonialidade do conhecimento (Mignolo, 2007), à colonialidade do ser (Maldonado-Torres, 2007) e à colonialidade das representações (Salazar, 2009; Schiwy, 2009) pois os oprimidos estão convencidos de sua inferioridade ao olhar para o mundo com os olhos dos opressores. Eles introjetam os padrões de dominação e até os reproduzem.

Os valores dos invasores passam a ser a pauta dos invadidos. Quanto mais se acentua a invasão, alienando o ser da cultura e o ser dos invadidos, mais estes quererão parecer com aqueles: andar como aqueles, vestir à sua maneira, falar a seu modo. (Freire, 2008, p. 200) 
A mídia comunitária indígena tem um papel importante no combate à invasão cultural, pois seus membros têm fortes raízes dentro das comunidades, salvaguardam e promovem a cultura e as línguas indígenas, atuando em favor dos interesses das comunidades. Elas constituem espaços-chave para a circulação de informações sobre o sistema-mundo e suas muitas ameaças, e são essenciais para formar e nomear o mundo em termos indígenas.

\section{A teoria da ação cultural dialógica}

Contrário à teoria da ação antidialógica, Freire discutiu a teoria da ação cultural dialógica. Ela também é constituída por quatro elementos: Colaboração, União, Organização e Síntese Cultural.

"Na teoria dialógica da ação, os sujeitos se encontram para a transformação do mundo em colaboração" (Freire, 2008, p. 218). A colaboração ocorre no nível do ser. Não é uma soma de individualidades, mas uma relação dialética em que dois outros se tornam dois eus. As comunidades indígenas têm uma base comunitária que possibilita a colaboração no sentido freiriano (Martinez Luna, 2013). A ação dialógica ocorre apenas entre sujeitos, em completa humanidade, com diferenças, mas não desigualdades. Para alcançar plenamente a ação dialógica nas comunidades, a igualdade de gênero é de extrema importância. As mulheres indígenas precisam ser integralmente reconhecidas por tudo o que fazem e trazem para a vida comunitária. Elas precisam ser capazes de exercer seus direitos. Da mesma maneira, os conflitos internos precisam ser resolvidos dentro das estações de rádio ou das comunidades. A construção da paz depende da colaboração entre os seres e somente pode ser concretizada pela comunicação.

A colaboração requer que os sujeitos se voltem para a realidade da qual dependem para problematizá-la, pronunciá-la e transformá-la enquanto são transformados por ela. A Ojo de Agua Comunicación fomenta a produção de diferentes produções radiofônicas, bem como canções e festivais de cinema, seminários, workshops e encontros no âmbito do projeto Comunicação Transformadora para o Cuidado da Vida e do Território. Todas essas ações têm constituído espaços para que vozes, saberes e ideias indígenas sejam pronunciados, ouvidos e circulados. São enunciações do sistema-mundo a partir das realidades dos povos indígenas. Elas analisam, criticam e conectam diversas formas de dominação que apontam que a exploração de territórios, culturas, indivíduos e meio ambiente fazem parte do que chamam de trama do poder, da qual buscam se libertar.

De acordo com Freire (2008), a libertação pode ser alcançada com a união dos oprimidos entre si e consigo mesmos. Para alcançar a união, os oprimidos 
aprendem os mecanismos e ideologias de sua adesão à realidade que os colonizou e lhes oferece uma falsa compreensão de si mesmos. A ação dialógica em unidade fornece o reconhecimento de como o sistema-mundo opera e como eles aderiram a ele para transformar uma realidade injusta.

Na busca da unidade, os oprimidos devem se organizar, pois a libertação é um esforço comum. Freire (2008) considerou os testemunhos elementos constitutivos da ação revolucionária. Eles permitem que os indivíduos compartilhem e construam uma visão de mundo unificada, uma percepção das contradições da sociedade e das possibilidades de mudança. Os testemunhos são veículos para a organização dos oprimidos. Enquanto na teoria antidialógica a manipulação é usada para a dominação, na teoria da ação dialógica, a organização e a participação das massas são necessárias para a libertação.

Segundo Freire (2008), "toda ação cultural é sempre uma forma sistematizada e deliberada de ação que incide sobre a estrutura social, ora no sentido de mantê-la como está ou mais ou menos como está, ora no de transformá-la" (p. 235). Daí, a ação cultural serve tanto à dominação quanto à libertação dos seres humanos. Quando colocada a serviço da libertação, a ação cultural busca superar as contradições antagonistas do sistema-mundo para deixar de lado a manipulação e a capitulação do eu (colonizado) ao outro (colonizador).

A pronúncia do mundo e a práxis do diálogo permitem que os indivíduos identifiquem o que Freire (2008) chamou de "geração temas", ou seja, os temas que são significativos para as pessoas de acordo com suas circunstâncias e em seus próprios termos. O projeto Comunicação Transformadora para o Cuidado da Vida e do Território tem três temas fundamentais que funcionam como temas geradores. Eles foram definidos pela Ojo de Agua e pelas emissoras indígenas que formam as nove rádios comunitárias. O gênero, a defesa da vida e do território e a construção da paz estão no centro da vida cotidiana nas comunidades indígenas não só em Oaxaca, mas em todo o mundo. Para Freire (2008), por meio do conhecimento emanado das conversas em torno dos temas geradores, a partir da práxis da palavra verdadeira, é possível se organizar e iniciar o processo da ação cultural, que ele chama de síntese cultural.

Considero diferentes produções midiáticas e atividades comunicativas derivadas do projeto Comunicação Transformadora para o Cuidado da Vida e do Território como exemplos da teoria da ação cultural dialógica de Freire. Os produtos de mídia e comunicação são discursos dialógicos que refletem a práxis de enunciar o mundo. Para discutir alguns exemplos, utilizo a teoria do dialogismo de Mikhail Bakhtin, pois ela fornece a base para a compreensão dos discursos midiáticos como elementos substantivos do diálogo. 


\section{A TEORIA DO DIALOGISMO DE BAKHTIN}

De acordo com Bakhtin (1986), o diálogo produz opiniões que levam à compreensão e à criação da possibilidade de mudança. $O$ dialogismo de Bakhtin presta especial atenção à multiplicidade de significados resultantes da percepção humana, porque o significado é o que torna um evento relevante, ou seja, a construção compartilhada de um evento entre diferentes indivíduos em um determinado tempo e espaço. Essa seria uma maneira de enunciar o mundo de perspectivas situadas em igualdade de condições, apesar das diferenças. Os povos indígenas de diferentes regiões do estado de Oaxaca (e do mundo) compartilham uma construção de suas realidades diante das ameaças do modelo de desenvolvimento do moderno sistema-mundo capitalista, colonial e patriarcal. A eles o direito de enunciar o mundo de acordo com sua perspectiva tem sido negado pelos opressores. No entanto, eles estão usando diversas tecnologias de mídia e comunicação para dar significados compartilhados aos eventos que ocorrem em seus territórios.

De acordo com Bakhtin (1986), o diálogo nos permite entender o lugar em que vivemos e a forma como nos relacionamos com ele. Isso está próximo da ideia da práxis do diálogo de Freire, que inclui ação e reflexão. A forma como a interação dialógica ocorre é por meio do intercâmbio de discursos, incluindo eventos discursivos. Para Bakhtin, a linguagem, como um código que permite que seus usuários compartilhem significados, é o elemento básico do discurso. Ken Hirschkop e David Sheperd (1989) afirmam que há uma variedade de estilos na articulação da linguagem que têm vários significados discursivos, dependendo dos contextos em que são usados. A diferenciação interna e a estratificação característica de qualquer língua é o que Bakhtin definiu como heteroglossia (citado em Holquist, 1981). A heteroglossia revela pontos de vista específicos sobre o mundo que se manifestam por meio das enunciações.

\section{As enunciações da mídia}

Uma enunciação pode ser uma única palavra, um romance ou um vídeo. É o produto da interação entre as especificidades da linguagem e do contexto (Todorov, 1984). De acordo com Todorov (1984), uma enunciação incorpora o entendimento e o posicionamento dos interlocutores em determinado contexto. Esse posicionamento torna possível que interlocutores e discurso, combinados, criem uma única coisa.

Considero enunciações as produções midiáticas criadas pelos indígenas e produtores de mídia comunitária do projeto Comunicação Transformadora para o Cuidado da Vida e do Território. Entendo-as como fenômenos sociais ancorados nos três temas centrais, que permitem a enunciação do mundo a 
partir das perspectivas e posicionamento dos povos indígenas. As enunciações não podem ser separadas de determinados interlocutores e de situações sociais específicas (Todorov, 1984). "Nenhum enunciado em geral pode ser atribuído exclusivamente ao orador; é o produto da interação dos interlocutores, e, em linhas gerais, o produto de toda a complexa situação social em que ocorreu" (Voloshinov, 1927, citado em Todorov, 1984, p. 30). Considero produtos de mídia como programas de rádio ou enunciações de podcasts, unidades de comunicação discursiva e de diálogo. As enunciações da mídia compartilham uma linguagem, um código que lhes dá significado. Elas não podem ser atribuídas apenas aos produtores de mídia e comunicadores, uma vez que são "o produto de toda a situação complexa em que [elas] ocorrem" (Todorov, 1984, p. 30). As enunciações midiáticas são resultado da interação entre os interlocutores e os eventos sociais durante os quais as enunciações são construídas, transmitidas, recebidas e compreendidas. Portanto, as declarações da mídia que discuto incorporam a expressão dos produtores de mídia, bem como a das comunidades, as diferentes estações de rádio, regiões de Oaxaca e até mesmo as de comunidades indígenas em outros países da América Latina.

Os produtores de mídia comunitária indígena dão sentido ao mundo de acordo com um tempo/lugar e contexto, e compartilham sua experiência e conhecimento sobre isso através de suas produções. Orientam suas diferentes enunciações midiáticas em direção a um objeto referencial, o modelo de desenvolvimento baseado no acúmulo por desapropriação, que se materializa em diversos projetos de natureza extrativista. Ao destacar esse objeto referencial, também abordam questões complexas e relevantes, como a violência, a desigualdade de gênero, a política, a distribuição de poder e riqueza, o fluxo de capital, a solidariedade global, a democracia, a liberdade, os direitos humanos e indígenas. As diferentes enunciações midiáticas se cruzam e se engajam em diálogos entre si. Esses diálogos buscam minar o discurso oficial das principais redes de mídia tradicionais e fontes oficiais do governo e corporativas.

\section{CONSIDERAÇÕES FINAIS}

Las Voces que Somos é uma série de rádio ao vivo, transmitida on-line e em diversas rádios comunitárias, em Oaxaca e outros territórios. A série foi produzida como parte do festival comunitário de cinema e rádio intitulado El Lugar que Habitamos, atividade anual organizada pela Ojo de Agua Comunicación como parte do projeto Comunicação Transformadora para o Cuidado da Vida e do Território. A série de rádio consiste em programas de rádio ao vivo com a participação de diferentes emissoras indígenas de diferentes estações de rádio 
no México e em outras partes da América Latina. Cada programa é dedicado a um tema principal relacionado ao cotidiano e às necessidades prementes dos povos indígenas. Em 2019, a série de rádio foi descrita da seguinte forma,

De diferentes cantos da América Latina, as vozes da terra se levantam, orgulhosas e dignas, para denunciar, aprender, refletir, propor e exigir respeito pela vida e pelos territórios. Um compromisso que exibe duas formas antagônicas de ver e estar nesse mundo: o modelo capitalista insustentável baseado no extrativismo e na desapropriação, versus a visão de Buen Vivir, a convivência harmoniosa com a Mãe Natureza, que preserva a vida em todas as suas manifestações no Lugar Que Habitamos. (Ojo de Agua Comunicación, s.d., para. 1)

A série incluiu emissoras comunitárias indígenas do México, Brasil e Colômbia. Foram três programas, intitulados: "Mulheres Fortes, Mundos Violentos"; “Tecendo a Vida, Luta Contra os Megaprojetos"; e "Nós Somos Vida, Somos Corações que Transformam". Em cada programa, foram inseridos trechos produzidos por diferentes mídias indígenas e comunitárias de Oaxaca, no Mexico, Brasil, Colômbia e Bolívia.

A série de rádio é um enunciado de mídia porque incorpora o posicionamento e a compreensão dos interlocutores sobre os temas geradores que escolheram discutir em certo tempo e espaço. Las Voces que Somos é o produto da interação dos interlocutores e do contexto social a partir do qual falam. Compartilhando a linguagem do rádio, há um significado subjacente comum entre os profissionais de mídia e comunicação sobre a oralidade do meio e os códigos para a produção de programas radiofônicos. Esse código comum permite que indivíduos de diferentes nações indígenas e diferentes países construam uma mensagem mediada. A série de rádio incorpora as vozes das pessoas que fazem o programa ao vivo, tanto quanto as de diferentes estações de rádio e coletivos de mídia por meio dos fragmentos sonoros incluídos em cada programa.

Os trechos sonoros incluem pequenas dramatizações, relatos jornalísticos do local, trechos informativos, músicas ou episódios de outras séries de rádio. Em cada programa da série, os temas variam. Alguns estão relacionados aos direitos das mulheres, à violência contra a mulher, às masculinidades, à migração, à exploração sexual. Outros lidam com as cosmovisões indígenas, a relação com a natureza e os territórios, o valor da água como fonte de vida. Também se referem a megaprojetos de natureza extrativista, como o Corredor Interoceânico na região do Istmo, rodovias na Amazônia boliviana, ou ao sistema-mundo capitalista, racista e patriarcal.

Las Voces que Somos, como um enunciado midiático, dá sentido ao mundo que os povos indígenas habitam. Incorpora a reflexão de diferentes indivíduos e 
comunidades, e é um produto mediado que clama por ações para transformar o mundo. Traz opiniões que levam à compreensão e à abertura de possibilidade de mudança de ideias, noções preconcebidas sobre os povos indígenas e sobre o desenvolvimento, e o discurso oficial manipulador.

Os programas de rádio, as conversas ao vivo e os trechos sonoros utilizados em cada transmissão descrevem e problematizam o mundo a partir de perspectivas indígenas. Discutem e analisam a agressão contra as mulheres, o capitalismo, o racismo, os megaprojetos, o desenvolvimento, a água, a vida, a história, as drogas, o álcool, a vida comum, entre outros temas. Eles também imaginam como o mundo poderia ou deveria ser. Por exemplo, com os homens indígenas ajudando em tarefas domésticas, ou governos cumprindo acordos internacionais e fornecendo serviços públicos de qualidade para as comunidades indígenas; além disso, a interrupção dos megaprojetos extrativistas ou as pessoas vivendo em relação harmoniosa com a natureza e entre si. Os programas de rádio contêm a multiplicidade de significados dos fenômenos ou temas que abordam. Esses significados sobre diferentes questões abordadas na série de rádio os tornam relevantes.

A enunciação da mídia é construída entre os diferentes indivíduos, indígenas e a mídia comunitária, bem como territórios situados em determinado tempo e espaço. Ela enuncia o mundo a partir de perspectivas situadas que, embora sejam únicas em suas especificidades, são comumente compartilhadas entre muitas comunidades indígenas da América Latina, que são oprimidas e cujos territórios correm o risco de ser saqueados. A enunciação da mídia permite que os povos indígenas deem sentido ao lugar em que vivem e a como se relacionam com ele. Mas também permite que o público se relacione com esses lugares e histórias a partir de suas próprias realidades situadas, apesar da natureza heteroglota da série radiofônica.

A heteroglossia é reconhecida na série de rádio desde o título Las Voces que Somos. Ele se refere a uma série de vozes, línguas e tipos de fala que expressam culturas, histórias, tradições e cosmovisões. A série é um enunciado da mídia feito em parceria por produtores indígenas de variadas mídias e diferentes povos indígenas. É uma conversa entre indivíduos com plena humanidade, com diferenças, mas não desigualdades. Assim, há um diálogo entre suas visões de mundo, que inclui os fragmentos sonoros que complementam a conversa entre as pessoas. O enunciado da mídia inclui sons dos territórios, música local, diferentes línguas, e traz ao programa a presença de mulheres, homens, jovens e crianças, bem como territórios e práticas culturais.

A série radiofônica é um veículo de autorrepresentação. Contém conhecimentos tradicionais e uma perspectiva contemporânea das questões globais, 
demonstrando que as culturas e os conhecimentos não estão estagnados. É um exercício dos direitos indígenas por meio da mídia, possibilitando a comunicação e exibindo a plena humanidade dos povos indígenas contra os opressores. É uma forma de buscar a emancipação.

A união de diferentes povos indígenas, vozes, culturas, música, tradições, conhecimentos em uma série de rádio congrega povos, indivíduos e territórios. Os enunciados de mídia incorporam a ação dialógica, que, segundo Freire, fornece o reconhecimento de como o sistema-mundo opera e de como transformá-lo. Os programas de rádio e os trechos sonoros afirmam a profunda compreensão que os povos indígenas possuem sobre como o sistema-mundo atua e como ele continua os oprimindo e marginalizando. Eles discutem a intersecção entre capitalismo, patriarcado e racismo em diferentes áreas da vida cotidiana, como os papéis familiares no cuidado das crianças e no trabalho doméstico, expressando as emoções, as lutas de mulheres indígenas e afro-americanas, as explorações sexuais, a migração forçada, os benefícios para poucos e não para as comunidades, a infraestrutura e os projetos de desenvolvimento, a falta de apoio governamental, para mencionar alguns temas.

A série de rádio é tanto um enunciado da mídia que inclui a heteroglossia de diversos indígenas, comunidades e territórios quanto a materialização de uma forma de organização de mídia e comunicadores. Como enunciado de mídia, se baseia fortemente em testemunhos, que Freire (2008) considerou como fontes de conhecimento crítico dos momentos históricos em que ocorre a ação dialógica. Os programas ao vivo e os fragmentos sonoros incluídos neles são testemunhos dos tempos e das formas de enfrentar suas ameaças e colher suas oportunidades. O enunciado midiático compartilha uma visão de mundo unificada de diferentes povos indígenas, evidenciando várias contradições da sociedade e mostrando possibilidades de mudança.

O enunciado de mídia Las Voces que Somos é uma contribuição concreta para a ação cultural indígena colocada a serviço da libertação. É um discurso que contraria a manipulação dos opressores e os discursos oficiais monolíticos sobre as culturas e o desenvolvimento indígena. É também um exemplo de autorrepresentação indígena que apresenta os indivíduos em sua plena humanidade, bem como culturas, saberes e cosmovisões, em igualdade de condições como os do sistema-mundo dominante ocidental e colonial. IM

\section{REFERÊNCIAS}

Bakhtin, M. (1986). Speech genres and other late essays (C. Emerson \& M. Holquist, Eds.; V. McGee, Trad.). University of Texas Press. 
Castellanos Guerrero, A., Gómez Izquierdo, J., \& Pineda, F. (2007). El discurso racista en México. In T. A. van Dijk (Coord.), Racismo y discurso en América Latina (pp. 285-332). Gedisa.

Castells i Talens, A. (2011). ¿Ni indígena ni comunitaria? La radio indigenista en tiempos neoindigenistas. Comunicación y Sociedad, (15), 123-142. https://bit.ly/3myZhWZ

Durán Matute, I., \& Moreno, R. (2021). La lucha por la vida frente a los megaproyectos en México. Cátedra Jorge Alonso. https://bit.ly/3mpRLyR

EDUCA, A.C. (2021). El Topil. Boletín de análisis y reflexión politica, (42). https://bit.ly/3zyIZl8

Freire, P. (2008). Pedagogía del oprimido. Siglo XXI.

Galtung, J. (1996). Peace by peaceful means. Sage.

Gómez Izquierdo, J., \& Sánchez, M. E. (2012). La ideología mestizante, el guadalupanismo y sus repercusiones sociales. Una revisión crítica de la identidad nacional. Benemérita Universidad Autónoma de Puebla; Universidad Iberoamericana, Puebla.

Harvey, D. (2005). El “nuevo" imperialismo: Acumulación por desposesión. Socialist Register 2004 (pp. 99-129). CLACSO.

Hirschkop, K., \& Sheperd, D. (Eds.). (1989). Bakhtin and cultural theory. Manchester University Press.

Holquist, M. (Ed.). (1981). The dialogic imagination. Four Essays by M. M. Bakhtin (C. Emerson \& M. Holquist, Trads.). University of Texas Press.

Instituto Nacional de Estadística Geografía e Informática. (2020). Presentación de Resultados. Censo de Población y Vivienda 2020.

Korsbaek, L., \& Sámano-Rentería, M. A. (2007). El indigenismo en México. Antecedentes y actualidad. Ra Ximhai, 3(1), 195-224. https://bit.ly/3jlnJe6

Magallanes-Blanco, C. (2016). Hablando de nuestra Madre: Videos indígenas sobre la naturaleza y el medio ambiente. In C. Magallanes-Blanco \& J. M. Ramos Rodríguez (Eds.), Miradas propias. Pueblos indígenas, comunicación y medios en la sociedad global (pp. 133-152). UIA Puebla; Ciespal.

Magallanes-Blanco, C., \& Di Lauro Bentivogli, G. (2021). Evaluación de un proyecto de comunicación, género, territorio y paz en Oaxaca, México [Manuscrito não publicado].

Magallanes-Blanco, C., \& Monteforte, G. (2019). Un engagement commun: Des médias autochtones et communautaires pour changer la réalité. In S. Gergaud \& T. M. Herrmann (Eds.), Cinémas autochtones: Des representations en mouvements (pp. 53-71). L'Harmattan.

Maldonado-Torres, N. (2007). On the coloniality of being. Cultural Studies, 21(2-3), 240-270. https://doi.org/10.1080/09502380601162548 
Martinez Luna, J. (2013). Textos sobre el camino andado (Tomo I). CMPIO; CAMPO; CEEESCI; CSEIIO.

Mignolo, W. D. (2007). Introduction: Coloniality of power and de-colonial thinking. Cultural Studies, 21(2-3), 155-167. https://doi. org/10.1080/09502380601162498

Nakata, M. (2014). Disciplining the savages. Savaging the disciplines. Aboriginal Studies Press.

Ojo de Agua Comunicación. (2020). Propuesta técnica de ayudas a proyectos [Manuscrito não publicado].

Ojo de Agua Comunicación. (s.d.). Las voces que somos. https://bit.ly/3jlrKiG

Quijano, A. (1998). Colonialidad del poder, cultura y conocimiento en América Latina. Ecuador Debate, (44), 227-238.

Salazar, J. F. (2009). Self-determination in practice: The critical making of indigenous media. Development in Practice, 19(4), 504-513. https://doi.org/10.1080/09614520902866397

Schiwy, F. (2009). Indianizing film. Decolonization, the Andes, and the question of technology. Rutgers University Press.

Smith, L. T. (2012). Decolonizing methodologies. Research and indigenous peoples. Zed Books; Otago University Press.

Sousa Santos, B. (2018). Construyendo las epistemologías del Sur: Para un pensamiento alternativo de alternativas. CLACSO.

Tischler, S. (2013). Revolución y destotalización. Grietas.

Todorov, T. (1984). Mikhail Bakhtin. The dialogical principle (Wlad Godzich, Trad.) (Theory and History of Literature, Vol. 13). University of Minnesota Press.

Walsh, C. (Ed.). (2013). Pedagogías decoloniales. Prácticas Insurgentes de resistir, (re)existir y (re)vivir (Tomo I). Abya Yala.

Zurita Cruz, M. (s.d.). La experiencia de formación en género para comunicadoras de nueve comunidades indígenas de Oaxaca [Manuscrito não publicado].

Artigo recebido em 7 de julho e aprovado em 15 de julho de 2021. 